\title{
Aging Affects Adaptation to Sound-Level Statistics in Human Auditory Cortex
}

\author{
DBjörn Herrmann, ${ }^{1}{ }^{\circledR}$ Burkhard Maess, ${ }^{2}$ and Ingrid S. Johnsrude ${ }^{1,3}$ \\ ${ }^{1}$ The Brain and Mind Institute, The University of Western Ontario, London, Ontario N6A 3K7, Canada, ${ }^{2}$ Max Planck Institute for Human Cognitive and \\ Brain Sciences, Magnetoencephalography and Cortical Networks Unit, 04103 Leipzig, Germany, and ${ }^{3}$ School of Communication Sciences and Disorders, \\ The University of Western Ontario, London, Ontario N6A 5B7, Canada
}

Optimal perception requires efficient and adaptive neural processing of sensory input. Neurons in nonhuman mammals adapt to the statistical properties of acoustic feature distributions such that they become sensitive to sounds that are most likely to occur in the environment. However, whether human auditory responses adapt to stimulus statistical distributions and how aging affects adaptation to stimulus statistics is unknown. We used MEG to study how exposure to different distributions of sound levels affects adaptation in auditory cortex of younger (mean: 25 years; $n=19$ ) and older (mean: 64 years; $n=20$ ) adults (male and female). Participants passively listened to two sound-level distributions with different modes (either 15 or $45 \mathrm{~dB}$ sensation level). In a control block with long interstimulus intervals, allowing neural populations to recover from adaptation, neural response magnitudes were similar between younger and older adults. Critically, both age groups demonstrated adaptation to sound-level stimulus statistics, but adaptation was altered for older compared with younger people: in the older group, neural responses continued to be sensitive to sound level under conditions in which responses were fully adapted in the younger group. The lack of full adaptation to the statistics of the sensory environment may be a physiological mechanism underlying the known difficulty that older adults have with filtering out irrelevant sensory information.

Key words: aging; auditory cortex; magnetoencephalography; neural adaptation; stimulus statistics

Significance Statement

Behavior requires efficient processing of acoustic stimulation. Animal work suggests that neurons accomplish efficient processing by adjusting their response sensitivity depending on statistical properties of the acoustic environment. Little is known about the extent to which this adaptation to stimulus statistics generalizes to humans, particularly to older humans. We used MEG to investigate how aging influences adaptation to sound-level statistics. Listeners were presented with sounds drawn from soundlevel distributions with different modes ( 15 vs $45 \mathrm{~dB}$ ). Auditory cortex neurons adapted to sound-level statistics in younger and older adults, but adaptation was incomplete in older people. The data suggest that the aging auditory system does not fully capitalize on the statistics available in sound environments to tune the perceptual system dynamically.

\section{Introduction}

Optimal behavior requires that perceptual systems process physical acoustic stimulation efficiently and adaptively (Lewicki, 2002; Wark et al., 2007; Kluender et al., 2013; Whitmire

\footnotetext{
Received May 29, 2017; revised Jan. 4, 2018; accepted Jan. 14, 2018

Author contributions: B.H. and I.S.J. designed research; B.H. performed research; B.H. and B.M. analyzed data; B.H., B.M., and I.S.J. wrote the paper.

This work was supported by the Canadian Institutes of Health Research (Grant MOP133450 to I.S.J.), and the Brain and Mind Institute at the University of Western Ontario (Postdoctoral Fellowship Award to B.H.). We thank the Max Planck Institute for Human Cognitive and Brain Sciences for the opportunity to record the data and Yvonne Wolff-Rosier and Heike Boethel for help during data acquisition.

The authors declare no competing financial interests.

Correspondence should be addressed to Björn Herrmann, The Brain and Mind Institute, The University of Western Ontario, London, Ontario N6A 5B7, Canada. E-mail: herrmann.b@gmail.com.

DOI:10.1523/JNEUROSCI.1489-17.2018

Copyright $\odot 2018$ the authors $\quad 0270-6474 / 18 / 381989-11 \$ 15.00 / 0$
}

and Stanley, 2016). However, neurons supporting perceptual inferences are inherently limited in the range with which they respond to sensory inputs (Laughlin, 1981). One way to overcome this limitation is to adjust dynamically a neuron's response range (input-output function) to statistical distributions of acoustic features in the environment in a process called adaptation to stimulus statistics, dynamic range adaptation, or gain control (Salinas and Thier, 2000; Dean et al., 2005, 2008; Nagel and Doupe, 2006; Wark et al., 2007; Robinson and McAlpine, 2009; Wen et al., 2009, 2012; Dahmen et al., 2010; Hildebrandt et al., 2011; Rabinowitz et al., 2011; Herrmann et al., 2014). Neural adaptation to stimulus statistics has been studied almost exclusively in nonhuman mammals and whether the results generalize to humans, particularly to older humans, is unknown. 
Adaptation to the statistics of acoustic environments is often studied using paradigms in which the sound-level statistics vary over different distributions ("environments"). Subcortical and cortical neurons in animals (guinea pigs, crickets, cats, songbirds, monkeys) adjust their response sensitivity to the mean sound level of a stimulus distribution (Dean et al., 2005, 2008; Nagel and Doupe, 2006; Watkins and Barbour, 2008; Wen et al., 2009, 2012; Hildebrandt et al., 2011; Robinson et al., 2016). In other words, a neuron's firing threshold shifts to a distribution's mean level such that the neuron is sensitive to sound levels above that mean level while avoiding response saturation. Adaptation to sound-level statistics ensures high sensitivity to a wide range of sound levels despite the limited range of a neuron (Dean et al., 2005; Robinson et al., 2016).

In humans, neural responses (measured using EEG or MEG) adapt to different sound-frequency distributions (Garrido et al., 2013; Herrmann et al., 2013a, 2014). Adaptation to sound-level (as opposed to sound-frequency) statistics has not been investigated despite this being crucial for avoiding neural response saturation in loud sound environments. Furthermore, older people and people with hearing impairment demonstrate phenomena such as hyperacusis (Baguley, 2003; Tyler et al., 2014) and loudness recruitment (Harris, 1953; Epstein and Marozeau, 2006) that are thought to be related to altered gain control along the auditory pathway (Knipper et al., 2013; Zeng, 2013). Dynamic control of neural gain is required for adaptation to stimulus statistics, but this may be impaired in older people.

Little is known about the extent to which adaptation to stimulus statistics may be affected by aging. Sensitivity to sound-frequency statistics appears to be unaffected in older people (Herrmann et al., 2013a). However, auditory cortex neurons of older adults seem to recover faster from neural adaptation compared with younger people (consistent with observations in older animals; de Villers-Sidani et al., 2010; Herrmann et al., 2016a). A consequence of reduced adaptation recovery times is that the history of sound stimulation is less reflected in the response to a current sound; that is, reduced recovery times would manifest as a smaller effect of sound-feature distributions on neural responses.

The current study uses MEG to investigate whether aging affects neural adaptation to sound-level statistics in auditory cortex. Younger and older adults listened to tones with sound levels that were drawn from sound-level distributions with different modes (either 15 or $45 \mathrm{~dB}$ ). Analyses focus on responses to tones for which the sound level, and the sound level of the directly preceding tone, are identical across sound-level distributions; this allows us to investigate the effects of longer-term sound-level statistics on neural adaptation.

\section{Materials and Methods}

Experimental design and statistical analysis. This study was not preregistered. Details of the critical variables and statistical tests for each specific analysis can be found in the subsections devoted to each analysis. In general, age group differences were either tested using an independentsamples $t$ test or via a between-subject factor in an ANOVA. Experimental manipulations (e.g., sound-level distributions) were dependent (repeated) factors. Differences between experimental manipulations were thus tested using a paired-samples $t$ test, a one-sample $t$ test, or via a within-subject factor in an ANOVA.

Herein, effect sizes are provided as partial $\eta$-squared $\left(\eta_{p}^{2}\right)$ when an ANOVA is reported and as $r_{\text {equivalent }}\left(r_{\mathrm{e}}\right)$ when a $t$ test is reported (Rosenthal and Rubin, 2003). $r_{\mathrm{e}}$ is equivalent to a Pearson productmoment correlation for two continuous variables, to a point-biserial correlation for one continuous and one dichotomous variable, and to the square root of partial $\eta^{2}$ for ANOVAs.
A Audiometric thresholds

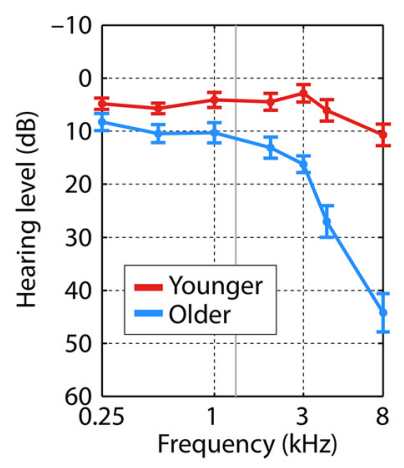

B Hearing threshold

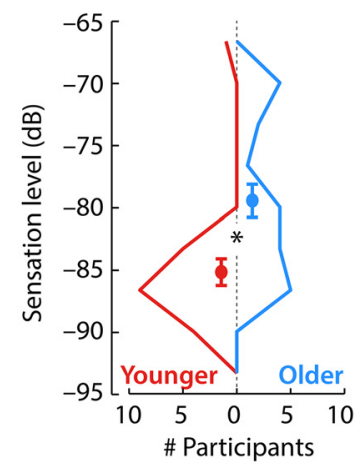

Figure 1. Hearing assessment. $A$, Results from audiometric testing for $14 / 19$ younger and $16 / 20$ older participants. The solid gray line at $1300 \mathrm{~Hz}$ marks the frequency of the tones used in the current study. B, Histogram of sensation levels (for a $1300 \mathrm{~Hz}$ tone) for younger and older participant groups. Dots and error bars reflect the mean level and SEM, respectively, for each group $\left({ }^{*} p<0.05\right)$. The sensation levels reflect $d B$ values from the threshold estimation procedure written in MATLAB.

Participants. Nineteen younger (mean: 25 years; range: $18-31$ years; 10 female) and 20 older (mean: 64 years; range: $54-71$ years; 10 female) adults participated in the current study. Participants reported no neurological disease or hearing impairment, gave written informed consent, and were paid for their participation. Data from one additional younger individual were excluded from the analysis because no response to a sound was observed even in blocks in which neurons could recover from adaptation. The study was conducted in accordance with the Declaration of Helsinki and approved by the Nonmedical Research Ethics Board of the University of Western Ontario (protocol ID: 106570).

Assessment of hearing abilities. Pure tone audiometric data were available for 14/19 younger and 16/20 older participants (Fig. 1A). For these participants, the pure tone average (i.e., the mean across the $0.25,0.5,1$, 2 , and $4 \mathrm{kHz}$ frequencies) was $<25 \mathrm{~dB}$ HL.

For each participant, we measured the hearing threshold (i.e., sensation level [SL]) for the tone frequency used in the current study $(1300 \mathrm{~Hz}$; see below). The mean hearing threshold was slightly elevated for older compared with younger adults (difference of $5.7 \mathrm{~dB}$; Fig. $1 B ; t_{37}=3.33$, $p=0.002, r_{\mathrm{e}}=0.480$ ), which is consistent with previous studies investigating hearing in healthy aging populations (Herrmann et al., 2013b, 2016a; Presacco et al., 2016) and with the audiometric data we acquired. No individual in the experiment (younger and older adults) had a hearing threshold $>20 \mathrm{~dB}$ above the mean hearing threshold of the younger adults.

To estimate the audiometric pure tone average in the participants for whom we were unable to measure audiometry, a linear function was fit to the pure tone average data from the 30 participants for which we had obtained the pure tone average as a function of the measured hearing threshold (in dB SL) for the $1300 \mathrm{~Hz}$ tone frequency. Based on the estimated coefficients from the linear function fit, we predicted the pure tone average for each of the remaining participants to be $<25 \mathrm{~dB}$ HL.

No statistically significant difference between age groups was observed in self-rated hearing abilities $\left(t_{36}=0.29 ; p=0.776, r_{\mathrm{e}}=0.048\right.$; assessed using a rating scale ranging from 0 to 10 ) or in self-reported speech perception $\left(t_{37}=0.88 ; p=0.382, r_{\mathrm{e}}=0.144\right)$, spatial hearing abilities $\left(t_{37}=1.02 ; p=0.314, r_{\mathrm{e}}=0.166\right)$, or quality of hearing $\left(t_{37}=1.24 ; p=\right.$ $\left.0.224, r_{\mathrm{e}}=0.199\right)$ as measured by a short German version of the Speech, Spatial, and Qualities of Hearing Scale (Gatehouse and Noble, 2004). Groups also did not differ on self-rated music abilities/experience $\left(t_{35}=\right.$ $1.63 ; p=0.113, r_{\mathrm{e}}=0.265$; rating scale range $\left.0-10\right)$.

The data suggest that the people who participated in the current study have clinically normal hearing relative to their age (despite the slight threshold elevation for older people).

Acoustic stimulation and procedure. All experimental procedures were performed in an electromagnetically shielded, sound-attenuating room. Sounds were presented via in-ear phones and the stimulation was con- 
Probability distributions

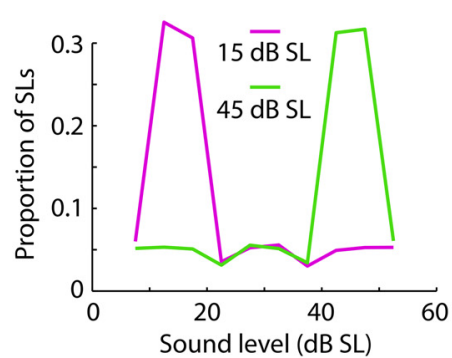

15-dB high-probability context

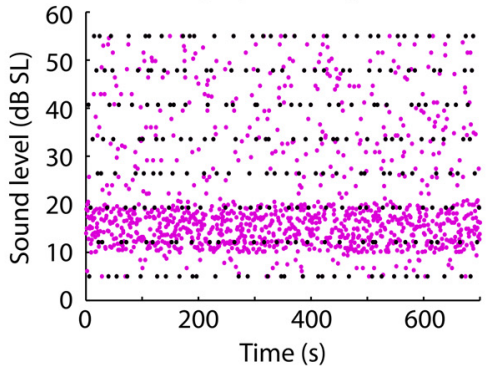

45-dB high-probability context

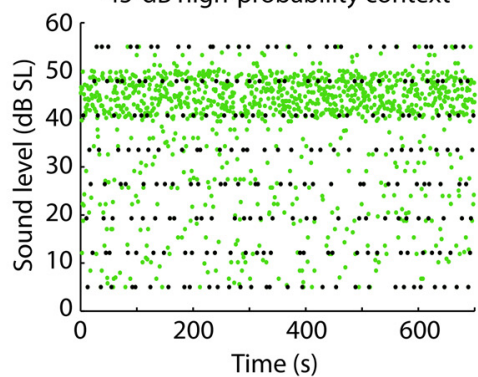

Figure 2. Experimental stimulation. Left, Example probability distributions used for acoustic stimulation for the two contexts: one with a modal sound level of $15 \mathrm{dBSL}$ and the other with a modal sound level of $45 \mathrm{~dB}$ SL. Middle/right, 1400 tones with different sound levels ( $y$-axis) were presented within a $700 \mathrm{~s}$ block ( $x$-axis). Each dot reflects the sound level of one tone. Black dots are the stimuli of interest: their level, and the level of the directly preceding tone, were identical across contexts.

trolled by a PC (Win XP, 64 Bit) running Psychtoolbox (version 3.0.11) in MATLAB (version 7.8.0.347).

In the beginning of the experimental session, the hearing threshold for a $1300 \mathrm{~Hz}$ sine tone was determined for each participant using a methodof-limits procedure (Leed, 2001). Tones of $15 \mathrm{~s}$ duration either decreased or increased in intensity by $4 \mathrm{~dB} / \mathrm{s}$ over time (decreasing and increasing trials were interleaved) and participants indicated when they could no longer hear the tone (intensity decrease) or when they started to hear the tone (intensity increase). The mean sound intensity at the time of the button press was noted for six decreasing trials and six increasing trials and these were averaged to determine the individual hearing threshold. All sounds in the MEG experiment were presented relative to the individual threshold (SL).

Tones were presented in two different types of stimulation blocks in the MEG experiment. Stimulation blocks differed with respect to the sound-level distributions from which a tone's sound level was drawn: for one block type, the modal sound level was $15 \mathrm{~dB}$ SL; for the other block type, it was $45 \mathrm{~dB}$ SL (Fig. 2). Critically, to investigate the effects of sound-level distribution (i.e., stimulus statistics) on neural responses, we eliminated the confounding effects of different acoustics by ensuring that the tones for which we analyzed neural responses as well as their local context (i.e., directly preceding tones) were identical across block types (i.e., 15 vs $45 \mathrm{~dB} \mathrm{SL}$ ), whereas the longer-term statistics were different between the two types of blocks.

The details of the sound stimulation during the MEG recordings were as follows. Participants listened to six blocks of sound stimulation, each 700 s long. In each block, 1400 tones were presented that had a frequency of $1300 \mathrm{~Hz}$ and a duration of $100 \mathrm{~ms}$. The onset-to-onset interval was kept constant at $500 \mathrm{~ms}$.

In each block, 8 tones with sound levels ranging from 5 to $55 \mathrm{~dB}$ SL (step size: $7.143 \mathrm{~dB}$ SL) were each presented 30 times, yielding 240 tones per block. These stimuli were identical across all six blocks (black dots in Fig. 2, middle/right). The 240 tones immediately preceding each of these $8 \times 30=240$ tones were also fixed such that, for each of the 30 presentations of 1 of the 8 sound levels, the sound level of the preceding tone took on 1 of 30 sound levels (range: $5-55 \mathrm{~dB}$ SL; step size: $1.724 \mathrm{~dB}$ SL) without replacement. Therefore, the same 240 pairs of experimental tones were presented in each block.

The sound levels for the remaining 920 tones (of the 1400 tones per block) were chosen randomly (range: $5-55 \mathrm{~dB}$ SL; step size: $0.1 \mathrm{~dB} \mathrm{SL}$ ) depending on the sound-level distribution (Fig. 2). For three of the six blocks, sound levels were randomly chosen from a sound-level distribution with a $15 \mathrm{~dB}$ high-probability region (purple dots in Fig. 2, middle). For the other three blocks, sound levels were randomly chosen from a sound-level distribution with a $45 \mathrm{~dB}$ high-probability region (green dots in Fig. 2, right). High-probability regions had a width of $10 \mathrm{~dB}$ centered on 15 or $45 \mathrm{~dB}$ SL (Fig. 2, left). The 480 experimental tones (i.e., 240 pairs) and the 920 filler tones were intermixed randomly in each block and presented such that at least one filler tone occurred between each of the 240 pairs of experimental tones. Blocks with different sound-level distributions alternated, and the starting sound-level distribution was counterbalanced across participants. Hereafter, we use "context" when referring to stimulus presentations based on the different sound-level distributions.

Analysis of the influence of sound-level context (statistics) on neural responses focused on the second tone in each pair of experimental tones: these were identical across the two sound-level distributions (black dots in Fig. 2, middle/right).

In a seventh block of trials (the "no-adaptation" block), participants were presented with the $1300 \mathrm{~Hz}$ tone 40 times at an onset-to-onset interval of $7 \mathrm{~s}$ and a sound level of $55 \mathrm{~dB}$ SL. Neural populations were assumed to be fully or almost fully recovered from adaptation during the time between the two tone presentations (Hari et al., 1982; Lü et al., 1992; Mäkelä et al., 1993; Sams et al., 1993; Budd et al., 1998; Zacharias et al., 2012). Therefore, we used this block to assess neural responses to tones when neurons are in a nonadapted state (see also Herrmann et al., 2014, 2015b).

$M E G$ recordings and preprocessing. MEG data were recorded using a 306-channel Neuromag Vectorview MEG (Elekta; sampling rate: 1000 $\mathrm{Hz}$, online filter: DC-330 Hz) at the Max Planck Institute for Human Cognitive and Brain Sciences in Leipzig, Germany. The signal space separation method was used to suppress external interference, interpolate bad channels, and transform individual data to a common sensor space, which allows comparison of topographical distributions across participants (Taulu et al., 2004, 2005).

Data were high-pass filtered $(0.7 \mathrm{~Hz} ; 2391$ points, Hann window), low-pass filtered $(30 \mathrm{~Hz}, 45$ points, Kaiser window), downsampled to 500 $\mathrm{Hz}$, and divided into 500-ms-long epochs time locked to sound onset (from $100 \mathrm{~ms}$ before to $400 \mathrm{~ms}$ after sound onset). Independent components analysis was used to remove noisy channels and activity related to eye movements and the heart (based on 120 randomly chosen data snippets of $10 \mathrm{~s}$ duration from the same preprocessing pipeline). Epochs comprising a signal change larger than 5 picoteslas $(\mathrm{pT})$ in any magnetometer channel or a signal change larger than $200 \mathrm{pT} / \mathrm{m}$ in any gradiometer channel were excluded.

Combination of magnetometer and gradiometer channels. To account for all data recorded, we combined signals from magnetometer and gradiometer channels. The Vectorview MEG device (Elekta) records magnetic fields using 102 magnetometers and 204 gradiometers in 102 locations distributed around the head. Magnetometers and gradiometers differ in their configuration, such that magnetometers measure magnetic fields in tesla $(\mathrm{T})$, whereas gradiometers (a coupled pair of magnetometers) measure differences in (the same) magnetic fields over a specified distance (i.e., $0.0168 \mathrm{~m}$ ) in tesla per meter $(\mathrm{T} / \mathrm{m})$. The combination of channel types requires accounting for their different units and thus requires scaling of the channels. For the current data, we rescaled all channels to tesla (i.e., to magnetometer channels) because such a model only requires a simple linear interpolation and it results in the same scaling for all channels. To this end, we applied the following rescaling matrix to each of the 102 sensor triplets (i.e., one triplet comprises two gradiometer channels and one magnetometer channel):

$$
X_{\text {scaled }}=S \times X
$$


where $X$ consists of a $3 \times n$ matrix (with $n$ being the number of data samples). The three rows of $X$ refer to the two gradiometers and one magnetometer (i.e., one triplet). $S$ refers to a $5 \times 3$ scaling matrix with the following elements (the value 0.0084 reflects half of the distance between the two gradiometer loops measured in meters and the rescaling constitutes a linear approximation of the magnetic field at each of the triplets) as follows:

$S=\begin{array}{ccc}-0.0084 & 0 & 1 \\ 0.0084 & 0 & 1 \\ 0 & -0.0084 & 1 \\ 0 & 0.0084 & 1 \\ 0 & 0 & 1\end{array}$

The rescaling replaces the sensor triplet by a sensor quintet of magnetometers. The columns of $S$ refer to the triplet of two gradiometers and one magnetometer and the rows of $S$ refer to the resulting five magnetometers.

Note that the results of this analysis combining sensor types yielded results very similar to those obtained by analyzing data from each channel type separately (figures for results from separate analyses of magnetometers and gradiometers can be found at https://osf.io/y5d4u/; see also Garcés et al., 2017).

Spatial filtering and source localization. To focus our analysis on auditory cortex activity, a spatial filter was calculated separately for each participant. To this end, a singular value decomposition was computed using the difference between a signal covariance matrix (based on data from $0-200 \mathrm{~ms}$ time locked to tone onset; averaged across the 40 trials in the "no-adaptation" block) and a noise covariance matrix (based on data from -100 to $0 \mathrm{~ms}$ before tone onset; averaged across the 40 trials in the no-adaptation block). The elements of the first eigenvector were used as spatial filter weights (for similar approaches, see Tesche et al., 1995; Uusitalo and Ilmoniemi, 1997; de Cheveigné and Simon, 2008; Garrido et al., 2013; Herrmann et al., 2016b). Spatial filtering reduced the highdimensional MEG data to a single virtual channel, mainly reflecting activity from auditory cortex. All subsequent analyses were performed using the data from this single virtual channel.

Anatomically constrained source localization was used to confirm the auditory cortex source underlying the spatial filter distribution. This analysis was performed for 14/19 younger adults and for 12/20 older adults for which individual T1-weighted MR images (3T Magnetom Trio; Siemens AG) were available. The MR images were used to construct inner skull surfaces (volume conductor) and midgray matter cortical surfaces (source model; using Freesurfer and MNE software; https://surfer.nmr.mgh.harvard.edu/; http:// www.martinos.org/mne/). The MR and the MEG coordinate systems were coregistered using MNE software that included an automated and iterative procedure that fitted the $>300$ digitized head surface points (Polhemus FASTRAK 3D digitizer) to the MR-reconstructed head surface (Besl and McKay, 1992). Lead fields were calculated from a boundary element model (inner skull; Nolte, 2003) using MNE software and Fieldtrip software and sLORETA inverse solutions (Pascual-Marqui, 2002) were calculated using custom MATLAB scripts. Differences in overall brain activation strength between participants were reduced by global mean normalization, which involved dividing the activation at each vertex by the mean activity across all vertices (separately for each participant). Neural activity was spatially smoothed across the surface using an approximation to a $6 \mathrm{~mm}$ FWHM Gaussian kernel (Han et al., 2006). Individual cortical representations were transformed to a common coordinate system (Fischl et al., 1999b) and finally morphed to the pial cortical surface of the brain of one participant for display purposes (Fischl et al., 1999a).

Responses to sounds for nonadapted neural populations. In a first analysis, we tested whether neural responses differed between age groups for tones presented every $7 \mathrm{~s}$ and for which neural populations are expected to be fully or almost fully recovered from neural adaptation (Hari et al., 1982; Lü et al., 1992; Mäkelä et al., 1993; Sams et al., 1993; Budd et al., 1998; Zacharias et al., 2012; Herrmann et al., 2014). To this end, the 40 single-trial time courses recorded in the no-adaptation block were averaged and the mean signal of the $100 \mathrm{~ms}$ pretone time window was subtracted from the signal at each time point (baseline correction). In a broad exploratory analysis, the signal at each time point was compared between age groups using independent $t$ tests. False discovery rate (FDR) correction was used to account for false positives among significant tests (Benjamini and Hochberg, 1995; Genovese et al., 2002).

Selection of analysis time windows. Neural adaptation is commonly investigated using the N100 component of the event-related potential (Butler, 1968; Hari et al., 1982; Lanting et al., 2013; Herrmann et al., 2015a) or the M100 component of the event-related magnetic field (Mäkelä et al., 1993; Sams et al., 1993; Zacharias et al., 2012; Okamoto and Kakigi, 2014). Suppression of neural responses by preceding stimulation has also been observed for the P50 (EEG) and M50 (MEG), here often referred to as sensory gating (Boutros and Belger, 1999; Müller et al., 2001; Rosburg et al., 2004). Therefore, we focused on M50 and M100 neural responses (i.e., magnetic fields at $\sim 50$ and $100 \mathrm{~ms}$ after stimulus onset, respectively) for our analyses.

Specifically, for each participant, the M100 amplitude was calculated as the average across a $10 \mathrm{~ms}$ time window centered on the individual's estimated peak latency from the no-adaptation responses. Note that this selection of the M100 time window is independent of the neural responses recorded in the blocks with different sound-level distributions: this approach is similar to the logic of functional localizers in MRI (Saxe et al., 2006; Poldrack, 2007; Fedorenko and Kanwisher, 2009). M50 amplitudes were calculated as the average signal in the 40-70 ms time window because there was no clear peak for younger participants in the no-adaptation block (Fig. $3 C$ ) that would allow the estimation of the peak latency separately for each participant (the time window is thus wider compared with the M100 to allow for response latency variability across participants).

Response sensitivity to sound level. To investigate how sound level affects response amplitude (averaged over contexts, i.e., sound-level distributions), trials from all adaptation blocks were sorted into one of five sound-level bins. $5-15,15-25,25-35,35-45$, and $45-55 \mathrm{~dB}$ SL, according to their sound level. Single-trial response time courses were averaged separately for each sound-level bin and the mean signal of the $100 \mathrm{~ms}$ pretone time window was subtracted from the signal at each time point (baseline correction).

For each participant, mean responses were extracted for the M50 and the M100. Overall response magnitude differences between age groups were assessed by averaging amplitudes across sound-level bins (separately for M50 and M100), followed by an independent $t$ test. To investigate whether responses increased with increasing sound level, a linear function was separately fit to the M50 and to the M100 amplitudes as a function of sound level (using the binned data). The slope of the linear function indicates the degree of response sensitivity to sound level. Slopes were tested against zero using a one-sample $t$ test (separately for younger and older adults). Age differences in response sensitivity were assessed by comparing the slopes between age groups using an independent $t$ test.

Context-dependent response sensitivity to sound level. For this analysis, only responses to the tones with the eight different critical sound levels (i.e., the 240 experimental tones per block) were analyzed (black dots in Fig. 2). The sound level of these tones and the sound level of the directly preceding tone were identical across sound-level distributions (i.e., 15 and $45 \mathrm{~dB}$ SL contexts). As a consequence of controlling the sound level of the tones that directly preceded the tones of interest, any effects of sound-level distribution ( 15 vs $45 \mathrm{~dB} \mathrm{SL}$ ) on neural responses must thus be due to the extended stimulation history and cannot be due to the sound level of the directly preceding tone.

The number of trials for each of the 8 sound levels in the different contexts was relatively low ( 90 trials $=30$ trials $\times 3$ blocks $)$. To increase the number of trials in the response average, thereby increasing the signal-to-noise ratio (Ingham and McAlpine, 2005), we averaged trials for two adjacent sound levels of the eight sound levels (separately for the $15 \mathrm{~dB}$ SL context and the $45 \mathrm{~dB}$ SL context). For example, single trials for sounds with the $5 \mathrm{~dB}$ SL and the $12.1 \mathrm{~dB}$ SL sound level were averaged (and the mean signal of the $100 \mathrm{~ms}$ pretone time window was subtracted from the signal at each time point; baseline correction). Averaging trials for 2 adjacent sound levels reduced the number of unique sound levels from 8 to 7 while doubling the number of trials in a unique response average. 

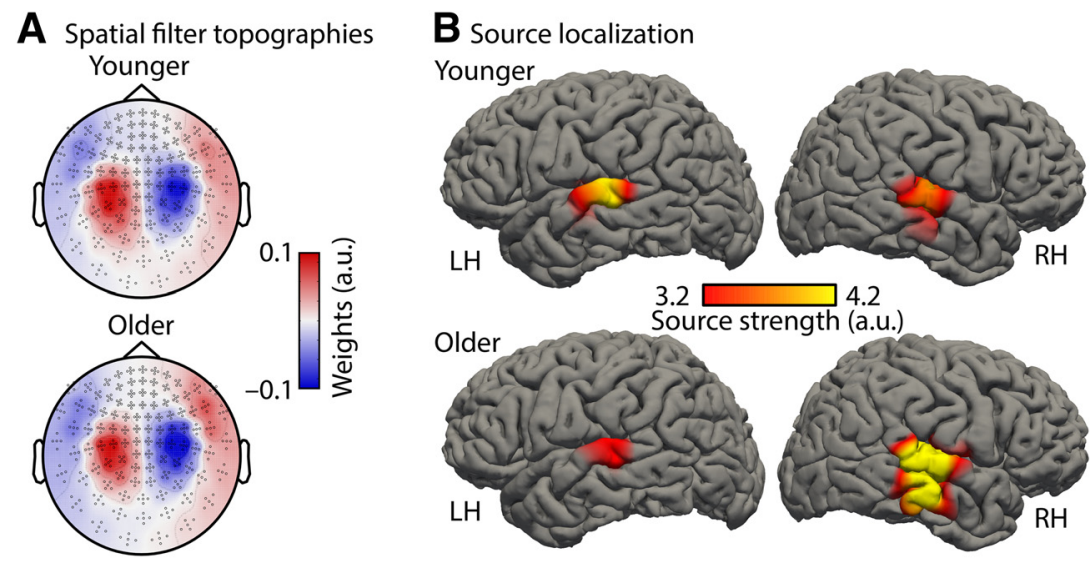

C Responses in 'no-adaptation' block

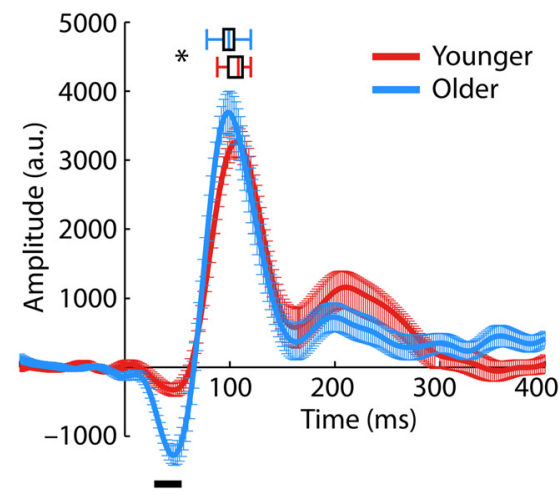

Figure 3. Spatial filter topographies and responses in the no-adaptation block. $A$, Spatial filter topographies for younger and older adults. B, Source localization of spatial filter topographies ( $L \mathrm{H}$, left hemisphere; RH, right hemisphere). Note that source localization could be performed for only 14/19 younger and 12/20 older participants for whom MRIs were available. The apparently larger right hemisphere source strength for older people, evident in $\boldsymbol{B}$, is probably an artifact of a relatively small dataset: note that it is not evident in $\boldsymbol{A}$, where topographies of all 20 older adults were averaged. $C$, Neural response time courses in the no-adaptation block (error bars reflect the SEM). The black line at the bottom indicates a significant difference between age groups ( $p<0.05$; FDR corrected). The box plots above the M100 wave show significantly earlier M100 latencies for older compared with younger adults ( $\left.{ }^{*} p<0.05\right)$.
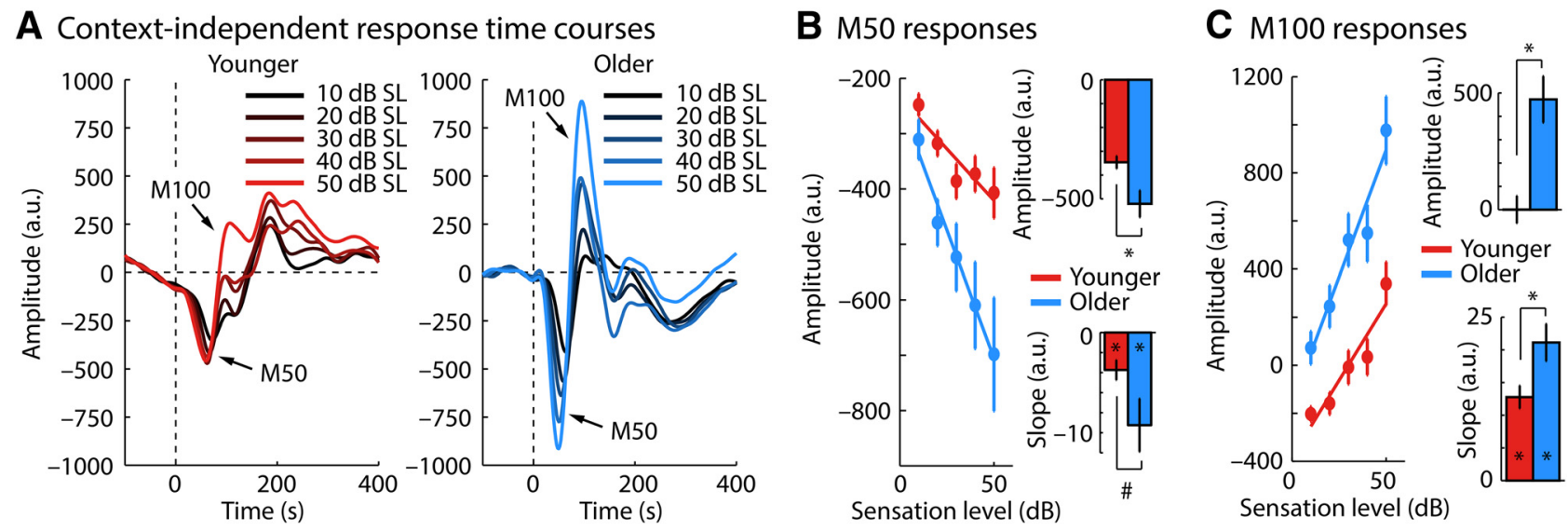

Figure 4. Response sensitivity to sound level averaged across adaptation blocks. $\boldsymbol{A}$, Response time courses for five different sound-level bins. $\boldsymbol{B}$, M50 response magnitudes as a function of sound level. The mean response across sound levels is shown on the top right. Amplitude change as a function of level (slope of a linear fit) is shown on the bottom right. Symbols within the bar reflect a significant difference from zero and symbols elsewhere depict significant differences between conditions ( ${ }^{*} p<0.05, \# p<0.10$ ). $\boldsymbol{C}$, Same as in $\boldsymbol{B}$ but for M100 response magnitudes. Error bars indicate SEM.

For each participant, context (15 or $45 \mathrm{~dB} \mathrm{SL})$, and sound level (7 levels), mean response amplitudes were calculated for the M50 and the M100. To investigate the sensitivity of the response amplitude to sound levels within the two stimulation contexts, the difference between the maximum and the minimum amplitude across sound levels was calculated (separately for each context). Note that we did not fit a linear function to assess response sensitivity because mean responses did not appear to change linearly with sound level, in particular for sound levels above the modal sound level of each distribution (see Fig. 6). The response differences were subjected to an ANOVA with the within-subject factor context ( $15 \mathrm{vs} 45 \mathrm{~dB} \mathrm{SL}$ ) and the between-subjects factor age group (younger vs older).

\section{Results}

Neural responses presented in subsequent sections originate from the virtual sensor calculated for each participant. That is, a spatial filter was constructed for each individual based on the response data in the no-adaptation block and all response time courses were projected through the spatial filter (Fig. $3 A$ ). Source localization confirmed that neural activity underlying spatial filter topographies originates from auditory cortex/superior temporal gyrus (Fig. 3B).
Responses to sounds for nonadapted neural populations

Neural responses to tones of $55 \mathrm{~dB}$ SL that were presented every $7 \mathrm{~s}$ (in the no-adaptation block) are depicted in Figure 3C. Comparing the amplitudes at each time point between age groups revealed a significant difference only in the M50 time window (FDR corrected). No age-related difference in amplitude was found in the time window of the M100. However, the M100 latency was smaller (i.e., earlier) in older compared with younger adults $\left(t_{37}=2.03, p=0.049, r_{\mathrm{e}}=0.317\right)$.

\section{Response sensitivity to sound level}

Figure $4 A$ shows response time courses from the adaptation blocks for older and younger listeners separately for different sound levels (across the two sound-level distributions). Mean response amplitude was larger for older compared with younger adults, both for the M50 $\left(t_{37}=2.742, p=0.009, r_{\mathrm{e}}=0.411\right.$; Fig. $4 B$, right top $)$ and for the $\operatorname{M100}\left(t_{37}=4.031, p=2.66 \times 10^{-4}\right.$, $r_{\mathrm{e}}=0.552$; Fig. $4 C$, right top). That is, despite the absence of an age group difference for the M100 response magnitude in the no-adaptation block, older adults exhibited larger M100 re- 
A $M 50$ responses in SL15 and SL45 contexts

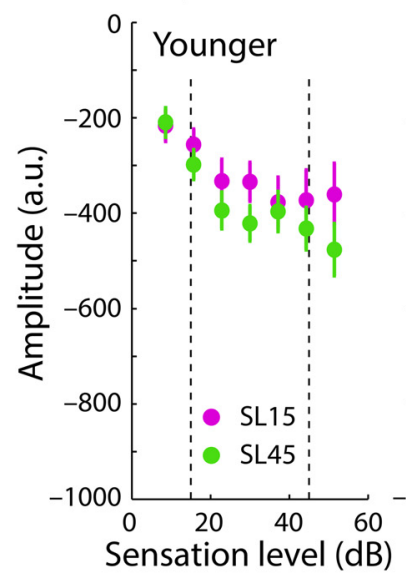

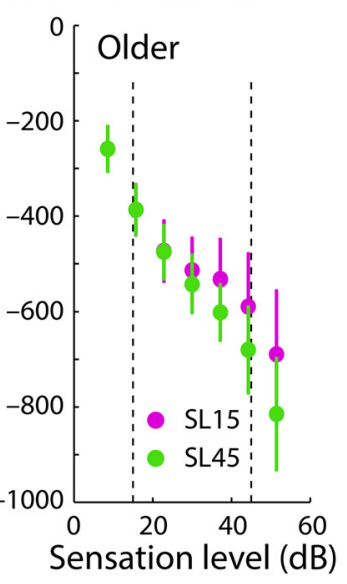
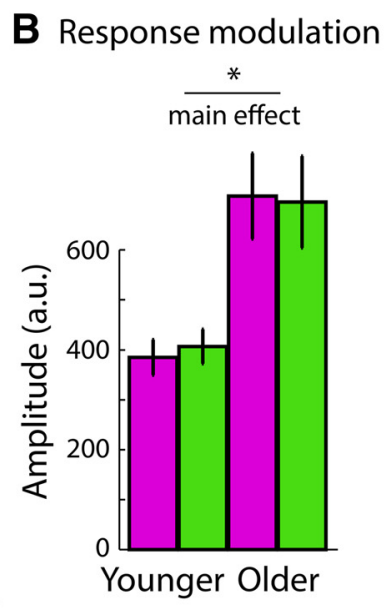

C Context difference (SL15-SL45)

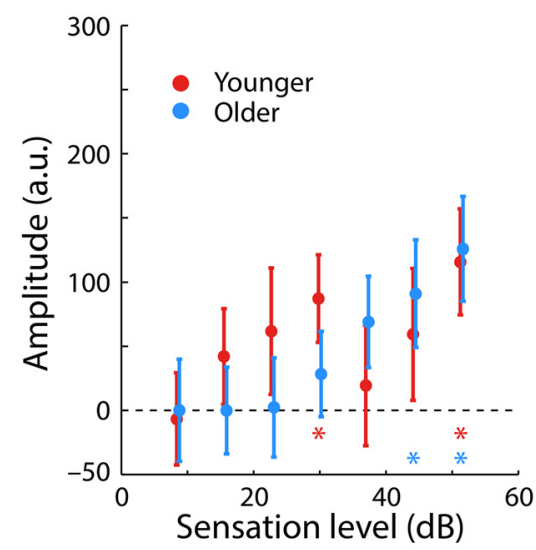

Figure 5. Context-dependent M50 response magnitudes. $\boldsymbol{A}$, Responses to different sound levels in the 15 and $45 \mathrm{~dB} \mathrm{SL}$ contexts. $\boldsymbol{B}$, Response range (calculated as the difference between the maximum and the minimum amplitude) in the 15 and $45 \mathrm{~dB} \mathrm{SL}$ contexts. The main effect of age group was significant ( $p<0.05$; no main effect of context and no interaction). $C$, Difference in response magnitude between the 15 and $45 \mathrm{dBSL}$ contexts for each sound level separately. The colored asterisks mark ${ }^{*}$ ) levels at which responses were significantly different between the 15 and the $45 \mathrm{~dB}$ SL context ( $p<0.05$, FDR corrected). Error bars indicate SEM.

sponse magnitudes when the presentation rate does not allow neurons to fully recover from adaptation.

The change in response amplitude as a function of sound level was quantified by fitting a linear function to M50 and M100 amplitudes. The slope of the linear fit reflects the degree of sensitivity to sound level. For M50 responses, slopes were significantly negative for both younger $\left(t_{18}=-3.695, p=0.002, r_{\mathrm{e}}=\right.$ $0.657)$ and older adults $\left(t_{19}=-3.493, p=0.002, r_{\mathrm{e}}=0.625\right)$. M50 responses were more sensitive to sound level in older compared with younger adults (more negative slope; Fig. $3 B$ ), but this difference was only marginally significant $\left(t_{37}=1.905, p=0.065\right.$, $\left.r_{\mathrm{e}}=0.299\right)$. For M100 responses, slopes were significantly positive for both younger $\left(t_{18}=7.237, p=9.91 \times 10^{-7}, r_{\mathrm{e}}=0.863\right)$ and older adults $\left(t_{19}=7.465, p=4.61 \times 10^{-7}, r_{\mathrm{e}}=0.864\right)$. M100 responses were more sensitive to sound level in older compared with younger adults (more positive slope; Fig. $4 C$; $t_{37}=2.473$, $\left.p=0.018, r_{\mathrm{e}}=0.377\right)$.

\section{Response sensitivity to sound level depends on context}

The results reported in this section are based on analyses of responses to tones for which the sound level and the sound level of the preceding tone were identical across contexts (i.e., soundlevel distributions). Any response differences between contexts must thus be due to the extended stimulation history and cannot be due to the sound level of the directly preceding tone. The results for the M50 are discussed before those for the M100.

Figure $5 A$ shows the M50 responses for tones in the 15 and 45 $\mathrm{dB}$ SL contexts. Figure $5 B$ depicts the response range for the two stimulation contexts and the two age groups (response range was calculated as the difference between the maximum amplitude and the minimum amplitude, across sound levels). The ANOVA revealed a main effect of age group $\left(F_{(1,37)}=10.895, p=0.002\right.$, $\left.\eta_{p}^{2}=0.228\right)$, indicating a larger M50 response range for older compared with younger adults. No effect of context $\left(F_{(1,37)}=\right.$ $\left.0.026, p=0.872, \eta_{p}^{2}<0.001\right)$ and no interaction $\left(F_{(1,37)}=0.300\right.$, $\left.p=0.587, \eta_{p}^{2}=0.008\right)$ was found. Figure $5 C$ shows the difference between the responses in the two contexts (sound-level distributions) separately for each sound level. Response differences were small overall and they were generally in the opposite direction to what would be expected. Responses should have been larger (i.e., more negative) for the $15 \mathrm{~dB}$ SL compared with the $45 \mathrm{~dB}$ SL context if response thresholds were aligned to the distribution's mode (Dean et al., 2005; Robinson et al., 2016). In contrast, for high sound levels, M50 responses were significantly smaller (i.e., more positive) in the $15 \mathrm{~dB}$ SL context compared with the $45 \mathrm{~dB}$ SL context, as indicated by the colored asterisks in Figure $5 C(p<$ 0.05 , FDR corrected). In other words, whereas M50 responses were sensitive to the sound level of a tone (Fig. $4 B$ ), responses were generally not very sensitive to changes in the distribution of sound levels in acoustic environments (Fig. $5 B, C$ ). The current experiment was designed to capitalize on the long adaptation time scales that have been demonstrated for M100 responses (Lü et al., 1992; Sams et al., 1993). Further research is required to investigate whether M50 responses are sensitive to changes in sound-level distributions using paradigms suitable to assess responses from neurons with short adaptation recovery times.

Figure $6 A$ shows the M100 responses for tones in the 15 and 45 $\mathrm{dB}$ SL contexts. The ANOVA calculated for the response range (i.e., the difference between the maximum amplitude and the minimum amplitude across sound levels) in the two contexts revealed a main effectt of context $\left(F_{(1,37)}=128.640, p=1.33 \times\right.$ $\left.10^{-13}, \eta_{p}^{2}=0.777\right)$ as well as a main effect of age group $\left(F_{(1,37)}=\right.$ 5.703, $\left.p=0.022, \eta_{p}^{2}=0.134\right)$. Neural responses were more sensitive to sound level in the $15 \mathrm{~dB}$ SL context than in the $45 \mathrm{~dB}$ SL context and response sensitivity was greater for older compared with younger adults (Fig. $6 B$ ). The context $\times$ age group interaction was not significant $\left(F_{(1,37)}=2.691, p=0.109, \eta_{p}^{2}=0.068\right)$. The direct comparison of each sound-level condition between the two sound-level distributions (Fig. $6 C$ ) revealed significantly larger responses for the $15 \mathrm{~dB}$ SL context compared with the 45 $\mathrm{dB}$ SL context for sound levels $>20 \mathrm{~dB}$ SL (colored asterisks in Fig. $6 C ; p<0.05$, FDR corrected).

The data for younger adults in Figure $6 \mathrm{~A}$ (left) show that neural response magnitudes increase sharply for sound levels equal or higher than the high-probability region of the soundlevel distributions, but remain largely unmodulated for lower sound levels (this is especially apparent for the $45 \mathrm{~dB}$ SL context; green dots in Fig. 6A, left). This context-dependent sensitivity to sound level is consistent with electrophysiological recordings in animals showing an adjustment of a neuron's firing threshold to the high-probability region of sound-level distributions and are a 
A M100 responses in SL15 and SL45 contexts

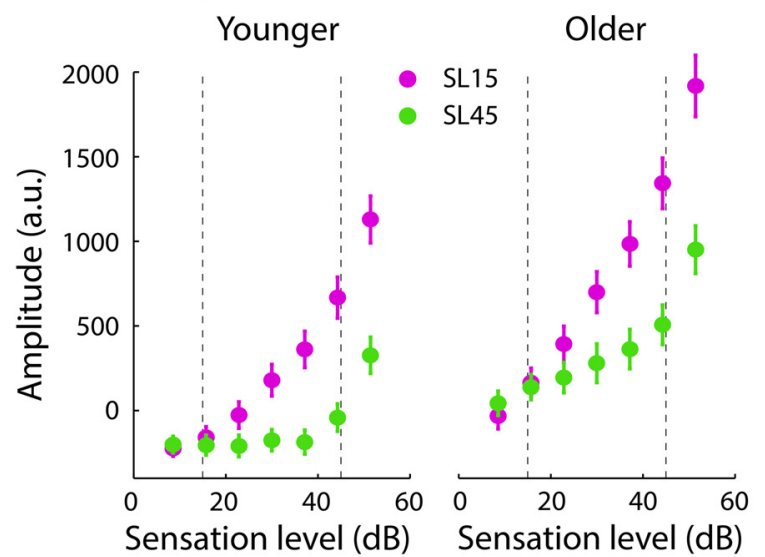

B Response modulation - SL15 SL45

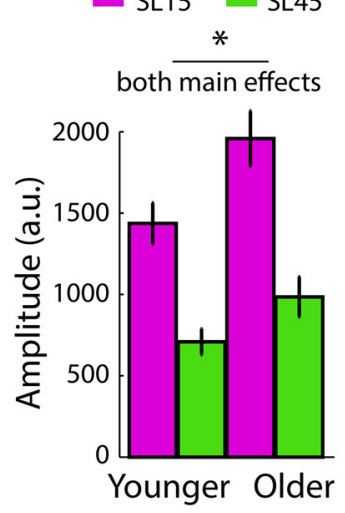

C Context Difference (SL15-SL45)

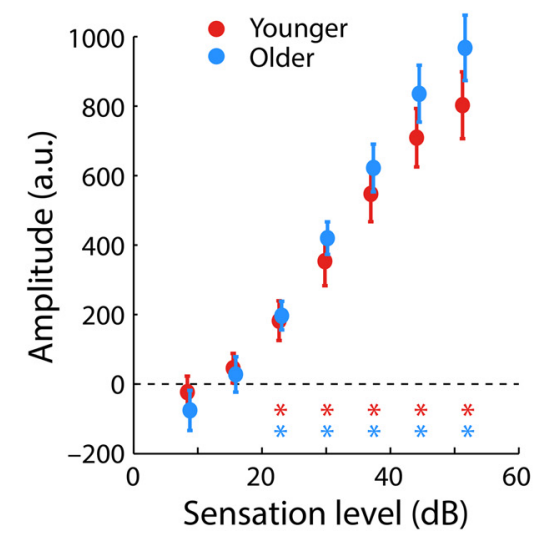

Figure 6. Context-dependent M100 response magnitudes. $\boldsymbol{A}$, Responses to different sound levels in the 15 and $45 \mathrm{~dB}$ SL contexts. $\boldsymbol{B}$, Response range (calculated as the difference between the maximum and the minimum amplitude) in the 15 and $45 \mathrm{dBSL}$ contexts. The main effect of age group and the main effect of context was significant ( $p<0.05$; no interaction). $C$, Difference in response magnitude between the 15 and $45 \mathrm{dBSL}$ contexts for each sound level separately. The colored asterisks mark $(*)$ levels at which responses were significantly larger (i.e., more positive) in the $15 \mathrm{~dB}$ SL compared with the $45 \mathrm{dBSL}$ context $(p<0.05$, FDR corrected). Error bars indicate SEM.

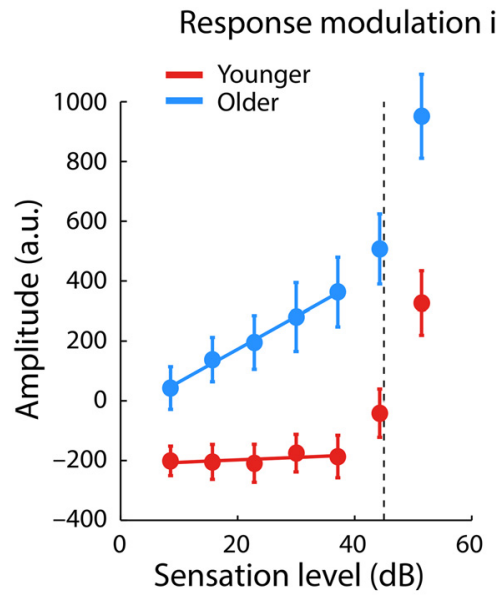

Figure 7. Response sensitivity to sound level in the $45 \mathrm{~dB}$ SL context for sound levels lower than the high-probability region. Left, Same data as that from the $45 \mathrm{dBSL}$ context displayed in Figure $6 \mathrm{~A}$. The dashed vertical line at $45 \mathrm{~dB} S \mathrm{~L}$ marks the center of the high-probability region. The colored solid lines reflect the averaged predicted values from participant-specific linear fits. Right, Slope of a linear function fit to responses as a function of the sound levels below the high-probability region revealed a response sensitivity for older but not for younger adults (right). ${ }^{*} p<0.05$. Error bars indicate SEM.

hallmark of adaptation to stimulus statistics (Dean et al., 2005; Hildebrandt et al., 2011; Robinson et al., 2016). However, neural responses for older adults (Fig. $6 \mathrm{~A}$, right) appear to be sensitive to sound levels below the high-probability region, which is particularly apparent for the $45 \mathrm{~dB}$ SL context. To quantify sensitivity to sound levels below the high-probability region in the $45 \mathrm{~dB}$ SL context, a linear function was fit to the M100 amplitudes across the five sound levels $<40 \mathrm{~dB}$ SL (separately for each participant). The estimated slope of the linear fit reflects the degree of sensitivity to sound levels. Separately for each age group, we tested the slope against zero using a one-sample $t$ test. The slope was significantly positive for older $\left(t_{19}=2.901, p=0.009, r_{\mathrm{e}}=0.554\right)$, but not for younger adults $\left(t_{18}=0.362, p=0.721, r_{\mathrm{e}}=0.085\right.$; Fig. 7). An independent-samples $t$ test revealed a larger slope, and thus a greater sensitivity of the M100 response to sound level, for older compared with younger adults $\left(t_{37}=2.269, p=0.029, r_{\mathrm{e}}=\right.$ $0.350)$. These analyses show that auditory cortex neurons in older, but not younger, adults remained sensitive to sound levels below a distribution's modal level.

\section{Controlling for sensation level differences between age groups}

The current study controlled for potential interindividual differences in audibility of a $1300 \mathrm{~Hz}$ tone by estimating the sensation level for each participant and presenting tones relative to this estimate. We have reported above that sensation levels differed slightly between age groups (Fig. 1): older individuals were presented with slightly louder tones (on average) compared with younger adults. To test whether the observed age differences in M100 context effects are also present if absolute sound levels are comparable between age groups, we selected 14 participants from each age group that were matched in their sensation levels. Therefore, for this subset of participants, no difference in the estimated sensation level (hearing threshold) was observed between age groups $\left(t_{26}=0.89, p=0.382, r_{\mathrm{e}}=0.172\right.$; Fig. $\left.8 A\right)$.

Figure $8 B$ shows the M100 neural response magnitudes for sounds in the 15 and $45 \mathrm{~dB}$ SL contexts. The ANOVA calculated for the response range (i.e., the difference between the maximum amplitude and the minimum amplitude across sound levels) in the two contexts revealed a main effect of context $\left(F_{(1,26)}=\right.$ $\left.100.462, p=2.02 \times 10^{-10}, \eta_{p}^{2}=0.794\right)$ as well as a main effect of age group $\left(F_{(1,26)}=5.314, p=0.029, \eta_{p}^{2}=0.170\right)$. Neural responses were more strongly level dependent in the $15 \mathrm{~dB}$ SL context compared with the $45 \mathrm{~dB}$ SL context and the level dependency was greater for older compared with younger adults (Fig. $8 B$ ). The context $\times$ age group interaction was not significant $\left(F_{(1,26)}=1.738, p=0.199, \eta_{p}^{2}=0.063\right)$.

To quantify sensitivity of the M100 amplitude to sound levels below the high-probability region in the $45 \mathrm{~dB}$ SL context, a linear function relating sound levels $<40 \mathrm{~dB}$ to response amplitude was fit (separately for each participant). The estimated slope of the linear fit was significantly positive for older $\left(t_{13}=2.822, p=\right.$ $\left.0.014, r_{\mathrm{e}}=0.616\right)$, but not for younger adults $\left(t_{13}=0.107, p=\right.$ $0.917, r_{\mathrm{e}}=0.030$; Fig. 8). An independent-samples $t$ test revealed a larger slope for older compared with younger adults $\left(t_{26}=\right.$ $2.100, p=0.045, r_{\mathrm{e}}=0.381$ ). The results, essentially identical to those from the main analysis, indicate that the different behavior 
A Hearing threshold

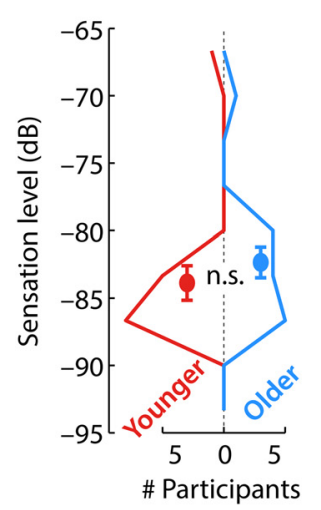

B M100 response magnitudes in SL15 and SL45 contexts

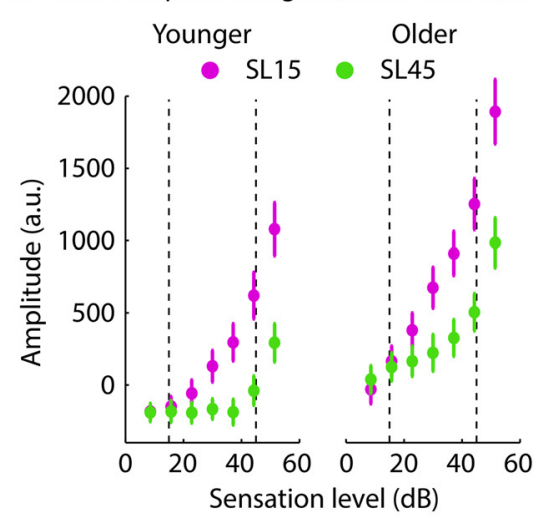

C Response modulation in SL45

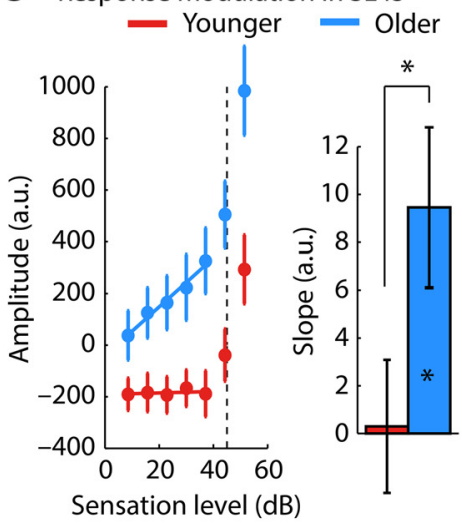

Figure 8. Context-dependent M100 response magnitudes, controlling for sensation level difference between age groups. $\boldsymbol{A}$, Histograms of sensation levels for the 14 selected participants of each age group. Dots and error bars reflect the mean sensation level and SEM, respectively, for each group. For this subset of participants, no difference in sensation level (hearing threshold) was observed between age groups (n.s., not significant; $p=0.382$ ). The sensation levels reflect $\mathrm{dB}$ values from the threshold estimation procedure written in MATLAB. $\boldsymbol{B}$, Responses to different sound levels in the 15 and $45 \mathrm{dBSL}$ contexts. Bar graphs show the response range in the 15 and $45 \mathrm{dBSL}$ contexts calculated as the difference between the maximum and the minimum response amplitude across sound levels. The main effect of age group as well as the main effect of context was significant ( $p<0.05$; no interaction). $C$, Sensitivity to sound level in the $45 \mathrm{~dB} S \mathrm{~L}$ context for levels lower than the high-probability region. Left, Data from the $45 \mathrm{dBSL}$ context displayed in $\boldsymbol{B}$. The dashed vertical line at $45 \mathrm{dBSL}$ marks the center of the high-probability region. The colored solid lines reflect the averaged predicted values from participant-specific linear fits. Right, Slope of a linear function relating sound level to response amplitudes below the high-probability region revealed a significantly positive slope for older but not for younger adults (right). ${ }^{*} p<0.05$. Error bars indicate SEM.

in older and younger listeners is probably not an artifact of slightly different stimulus levels in the two groups.

\section{Discussion}

The current study investigated whether aging affects adaptation to sound-level statistics in auditory cortex. Individuals listened to tones with a sound level that was drawn either from a distribution with a modal sound level of $15 \mathrm{~dB}$ SL or from a distribution with a modal sound level of $45 \mathrm{~dB}$ SL. Responses (M100) were comparable between younger and older adults when neural populations were recovered from adaptation. Critically, both age groups showed adaptation to sound-level statistics, but adaptation to the statistics was altered for older compared with younger adults. That is, neural responses in older people continued to be sensitive to sound level under conditions in which responses were not sensitive to sound level (fully adapted) in younger people.

\section{Neural adaptation to stimulus statistics}

M100 responses were sensitive to sound-level distributions (Fig. 6). The increase in M100 amplitude with increasing sound level was larger for the sound-level distribution with a low mode (15 $\mathrm{dB} S \mathrm{SL}$ ) compared with the sound-level distribution with a high mode ( $45 \mathrm{~dB} \mathrm{SL})$. The response threshold appeared to be aligned with the high-probability region of a distribution (i.e., lower for the $15 \mathrm{~dB}$ SL context compared with the $45 \mathrm{~dB}$ SL context; Fig. 6). That is, neural populations in human auditory cortex were sensitive to sound levels around and above the mode of the distributions. This adaptation to sound-level distributions avoids response saturation and ensures sensitivity to a wide range of sound levels despite the limited response range of neurons.

The current human data are consistent with animal studies showing neural adaptation to stimulus statistics (Kvale and Schreiner, 2004; Dean et al., 2005; Nagel and Doupe, 2006; Watkins and Barbour, 2008; Wen et al., 2009; Dahmen et al., 2010; Hildebrandt et al., 2011; Rabinowitz et al., 2011; Wen et al., 2012). For example, electrophysiological recordings from guinea pigs and crickets show that neurons shift their response threshold depending on the mean of a sound-level distribution (Dean et al., 2005; Hildebrandt et al., 2011; Robinson et al., 2016) such that, similar to the current results, neural responses are sensitive to sound levels above the distribution's high-probability region (Dean et al., 2005; Robinson et al., 2016). Together with previous work in humans on neural adaptation to sound-frequency distributions (Garrido et al., 2013; Herrmann et al., 2013a, 2014) and observations of behavioral sensitivity to sound-level distributions (Simpson et al., 2014), the current data demonstrate that neurons in the auditory system of humans adjust their response range dynamically depending on the statistics of the sound environment.

The current results are also consistent with recent studies investigating the effects of temporal context on neural adaptation of N1/M100 responses. N1/M100 amplitudes are influenced by the extended history of tone presentations (Costa-Faidella et al., 2011; Zacharias et al., 2012; Okamoto and Kakigi, 2014; Herrmann et al., 2016a) and not just by the time interval between the preceding and current stimulus (Budd et al., 1998; Rosburg et al., 2006, 2010; Zhang et al., 2011), which had long been the preferred view based on isochronous tone stimulation. The propensity of auditory cortex neurons to remain sensitive to stimuli that have been presented in the extended past may be crucial for short-term adaptation to featural distributions in sound environments and may be important for sensory memory and for filtering out irrelevant aspects of sound environments.

\section{Aging affects neural response magnitudes and adaptation to stimulus statistics}

When tones were presented every $7 \mathrm{~s}$ and neural populations had time to recover from neural adaptation, M100 amplitudes did not differ between age groups (despite larger M50 amplitudes and shorter M100 latencies in older people). Therefore, any age differences for M100 amplitudes to tones presented at a fast presentation rate $(0.5 \mathrm{~s}$; in blocks testing the effects of sound-level distributions) must be due to changes in adaptation properties of auditory cortex neurons.

When tones were presented every $0.5 \mathrm{~s}$, we observed larger overall M50 and M100 responses and a larger sensitivity to sound levels for older compared with younger people (Fig. 4). These data are consistent with previous work in humans: an overampli- 
fication of cortical responses (Tremblay et al., 2003; Harkrider et al., 2005; Sörös et al., 2009; Herrmann et al., 2013b; Bidelman et al., 2014; Presacco et al., 2016; Stothart and Kazanina, 2016) and a larger sensitivity to sound levels (Cody et al., 1968; Laffont et al., 1989; Morita et al., 2003) have been shown to correlate with aging and hearing loss. Previous results further suggest that auditory cortex neurons recover from adaptation more quickly in the time in older compared with younger individuals (see also de VillersSidani et al., 2010; Herrmann et al., 2016a). This may lead to the observed response overamplification for older people because neurons may have recovered more between tone presentations. This interpretation is consistent with data from younger adults showing a greater sensitivity to sound level when neurons are less adapted (Keidel and Spreng, 1965; Müller and Stange, 1971) and with the current data showing an age-related response overamplification in adaptation blocks.

Based on previous data suggesting faster recovery from adaptation in the auditory cortex of older people (Herrmann et al., 2016a), we expected that the neural responses in this group would be less influenced by the statistics of the extended stimulation history. In contrast to our initial prediction, responses within the $15 \mathrm{~dB}$ SL context and the $45 \mathrm{~dB}$ SL context appeared equally dependent on sound level in both age groups, suggesting that neurons in both age groups were adapting to sound-level distributions (Fig. 6C). However, adaptation to stimulus statistics was altered in older adults. Response amplitude depended on sound level at levels below the distribution's mode for older but not for younger individuals (Fig. 7). The inability to fully adapt to the statistics in acoustic environments might underlie the difficulty that older people experience in filtering out irrelevant information.

\section{Potential mechanisms underlying age-related changes in adaptation to stimulus statistics}

Adaptation to stimulus statistics is likely supported by multiple mechanisms (Silver, 2010; Isaacson and Scanziani, 2011; Whitmire and Stanley, 2016) that may involve ascending and descending neural pathways (Robinson et al., 2016) and local (withinregion) circuitry (King et al., 2016). Several studies suggest that neural inhibition is crucial for shaping a neuron's input-output function and dynamic response range (Ingham and McAlpine, 2005; Olsen and Wilson, 2008; Carvalho and Buonomano, 2009; Hildebrandt et al., 2011; Wilson et al., 2012), whereas others emphasize the role of excitation (Sato et al., 2016) and synaptic depression (Abbott et al., 1997).

The current age-related response enhancements are consistent with animal studies reporting a response overamplification along the ascending auditory pathway in older animals and animals with hearing loss (Popelár et al., 1987; Syka et al., 1994; Hughes et al., 2010; Stolzberg et al., 2012; Möhrle et al., 2016; Herrmann et al., 2017; Salvi et al., 2016). Response overamplification due to aging and hearing loss is thought to result from reduced neural inhibition (Caspary et al., 2008; Takesian et al., 2009, 2012; Rabang et al., 2012; Salvi et al., 2016) and increased excitation (Salvi et al., 2016) and may underlie loudness recruitment and hyperacusis (Knipper et al., 2013; Zeng, 2013). Given the multifaceted mechanisms that appear to underlie adaptation to stimulus statistics, determining how aging affects those mechanisms may be challenging. Nevertheless, the age-related reduction of neural inhibition in auditory cortex may contribute critically to the changes in adaptation to stimulus statistics observed in older people.

Previous work in animals indicates that reduced inhibition and response overamplification due to aging and hearing impair- ment is particularly expressed in supragranular (upper) layers of auditory cortex (Ling et al., 2005; Hughes et al., 2010; Llano et al., 2012; Stolzberg et al., 2012). The supragranular layers include dendritic arbors of corticofugal pyramidal neurons residing in deeper infragranular layers, which provide modulatory feedback to subcortical brain structures (cf. Sherman and Guillery, 1998; Winer and Lee, 2007). These corticofugal projections may be important for the modulation of subcortical activity by cognitive factors such as attention (Suga et al., 2000). Overamplification and changes in adaptation to stimulus statistics may therefore reflect only one manifestation of cortical changes associated with aging and sensorineural hearing impairment. Age-related alterations of neural gain in the supragranular layers of mammalian auditory cortex may also affect how corticofugal pyramidal neurons modulate activity in subcortical structures and thus how sensory processes and cognitive factors interact in support of perception.

\section{Conclusions}

The current MEG study investigated how aging affects adaptation to sound-level statistics in auditory cortex. Neural populations in younger and older people adapted to sound-level distributions that differed in modal sound level. However, adaptation to sound-level statistics was altered in older people such that responses were affected by sound level under conditions resulting in full adaptation of neural responses (and no sensitivity to level) in younger people. The current data thus suggest an age-related impairment in using sound-level statistics to change neural response sensitivity in sensory environments, which may explain some of the phenomena of age-related hearing impairment, such as hyperacusis, loudness recruitment, and abnormal salience of distracting sounds.

\section{References}

Abbott LF, Varela JA, Sen K, Nelson SB (1997) Synaptic depression and cortical gain control. Science 275:220-224. Medline

Baguley DM (2003) Hyperacusis. J R Soc Med 96:582-585. Medline

Benjamini Y, Hochberg Y (1995) Controlling the false discovery rate: a practical and powerful approach to multiple testing. Journal of the Royal Statistical Society Series B 57:289-300.

Besl PJ, McKay ND (1992) A method for registration of 3-D shapes. IEEE Transactions on Pattern Analysis and Machine Intelligence 14:239-256. CrossRef

Bidelman GM, Villafuerte JW, Moreno S, Alain C (2014) Age-related changes in the subcorticalecortical encoding and categorical perception of speech. Neurobiol Aging 35:2526-2540. CrossRef Medline

Boutros NN, Belger A (1999) Midlatency evoked potentials attenuation and augmentation reflect different aspects of sensory gating. Biol Psychiatry 45:917-922. CrossRef Medline

Budd TW, Barry RJ, Gordon E, Rennie C, Michie PT (1998) Decrement of the N1 auditory event-related potential with stimulus repetition: habituation vs. refractoriness. Int J Psychophysiol 31:51-68. CrossRef Medline

Butler RA (1968) Effect of changes in stimulus frequency and intensity on habituation of the human vertex potential. J Acoust Soc Am 44:945-950. CrossRef Medline

Carvalho TP, Buonomano DV (2009) Differential effects of excitatory and inhibitory plasticity on synaptically driven neuronal input-output functions. Neuron 61:774-785. CrossRef Medline

Caspary DM, Ling L, Turner JG, Hughes LF (2008) Inhibitory neurotransmission, plasticity and aging in the mammalian central auditory system. J Exp Biol 211:1781-1791. CrossRef Medline

Cody DT, Griffing T, Taylor WF (1968) Assessment of the newer tests of auditory function. Ann Otol Rhinol Laryngol 77:686-705. CrossRef Medline

Costa-Faidella J, Grimm S, Slabu L, Díaz-Santaella F, Escera C (2011) Multiple time scales of adaptation in the auditory system as revealed by human evoked potentials. Psychophysiology 48:774-783. CrossRef Medline 
Dahmen JC, Keating P, Nodal FR, Schulz AL, King AJ (2010) Adaptation to stimulus statistics in the perception and neural representation of auditory space. Neuron 66:937-948. CrossRef Medline

Dean I, Harper NS, McAlpine D (2005) Neural population coding of sound level adapts to stimulus statistics. Nat Neurosci 8:1684-1689. CrossRef Medline

Dean I, Robinson BL, Harper NS, McAlpine D (2008) Rapid neural adaptation to sound level statistics. J Neurosci 28:6430-6438. CrossRef Medline

de Cheveigné A, Simon JZ (2008) Denoising based on spatial filtering. J Neurosci Methods 171:331-339. CrossRef Medline

de Villers-Sidani E, Alzghoul L, Zhou X, Simpson KL, Lin RC, Merzenich MM (2010) Recovery of functional and structural age-related changes in the rat primary auditory cortex with operant training. Proc Natl Acad Sci U S A 107:13900-13905. CrossRef Medline

Epstein MJ, Marozeau J (2006) Loudness and intensity coding. In: Oxford handbook of auditory science: hearing (Plack CJ, ed), pp 45-67. Oxford: OUP.

Fedorenko E, Kanwisher N (2009) Neuroimaging of language: why Hasn't a clearer picture emerged? Language and Linguistics Compass 3:1-27. CrossRef

Fischl B, Sereno MI, Dale AM (1999a) Cortical surface-based analysis II: inflation, flattening, and a surface-based coordinate system. Neuroimage 9:195-207. CrossRef Medline

Fischl B, Sereno MI, Tootell RB, Dale AM (1999b) High-resolution intersubject averaging and a coordinate system for the cortical surface. Hum Brain Mapp 8:272-284. CrossRef Medline

Garcés P, López-Sanz D, Maestú F, Pereda E (2017) Choice of magnetometers and gradiometers after signal space separation. Sensors (Basel) 17: pii: E2926. CrossRef Medline

Garrido MI, Sahani M, Dolan RJ (2013) Outlier responses reflect sensitivity to statistical structure in the human brain. PLoS Comput Biol 9:e1002999. CrossRef Medline

Gatehouse S, Noble W (2004) The speech, spatial and qualities of hearing scale (SSQ). Int J Audiol 43:85-99. CrossRef Medline

Genovese CR, Lazar NA, Nichols T (2002) Thresholding of statistical maps in functional neuroimaging using the false discovery rate. Neuroimage 15:870-878. CrossRef Medline

Han X, Jovicich J, Salat D, van der Kouwe A, Quinn B, Czanner S, Busa E, Pacheco J, Albert M, Killiany R, Maguire P, Rosas D, Makris N, Dale A, Dickerson B, Fischl B (2006) Reliability of MRI-derived measurements of human cerebral cortical thickness: the effects of field strength, scanner upgrade and manufacturer. Neuroimage 32:180-194. CrossRef Medline

Hari R, Kaila K, Katila T, Tuomisto T, Varpula T (1982) Interstimulus interval dependence of the auditory vertex response and its magnetic counterpart: implications for their neural generation. Electroencephalogr Clin Neurophysiol 54:561-569. CrossRef Medline

Harkrider AW, Plyler PN, Hedrick MS (2005) Effects of age and spectral shaping on perception and neural representation of stop consonant stimuli. Clin Neurophysiol 116:2153-2164. CrossRef Medline

Harris JD (1953) A brief critical review of loudness recruitment. Psychol Bull 50:190-203. CrossRef Medline

Herrmann B, Henry MJ, Obleser J (2013a) Frequency-specific adaptation in human auditory cortex depends on the spectral variance in the acoustic stimulation. J Neurophysiol 109:2086-2096. CrossRef Medline

Herrmann B, Henry MJ, Scharinger M, Obleser J (2013b) Auditory filter width affects response magnitude but not frequency specificity in auditory cortex. Hear Res 304:128-136. CrossRef Medline

Herrmann B, Schlichting N, Obleser J (2014) Dynamic range adaptation to spectral stimulus statistics in human auditory cortex. J Neurosci 34:327331. CrossRef Medline

Herrmann B, Henry MJ, Fromboluti EK, McAuley JD, Obleser J (2015a) Statistical context shapes stimulus-specific adaptation in human auditory cortex. J Neurophysiol 113:2582-2591. CrossRef Medline

Herrmann B, Parthasarathy A, Han EX, Obleser J, Bartlett EL (2015b) Sensitivity of rat inferior colliculus neurons to frequency distributions. J Neurophysiol 114:2941-2954. CrossRef Medline

Herrmann B, Henry MJ, Johnsrude IS, Obleser J (2016a) Altered temporal dynamics of neural adaptation in the aging human auditory cortex. Neurobiol Aging 45:10-22. CrossRef Medline

Herrmann B, Henry MJ, Haegens S, Obleser J (2016b) Temporal expectations and neural amplitude fluctuations in auditory cortex interactively influence perception. Neuroimage 124:487-497. CrossRef Medline
Herrmann B, Parthasarathy A, Bartlett EL (2017) Aging affects dual encoding of periodicity and envelope shape in rat inferior colliculus neurons. Eur J Neurosci 45:299-311. CrossRef Medline

Hildebrandt KJ, Benda J, Hennig RM (2011) Multiple arithmetic operations in a single neuron: the recruitment of adaptation processes in the cricket auditory pathway depends on sensory context. J Neurosci 31:1414214150. CrossRef Medline

Hughes LF, Turner JG, Parrish JL, Caspary DM (2010) Processing of broadband stimuli across A1 layers in young and aged rats. Hear Res 264:79-85. CrossRef Medline

Ingham NJ, McAlpine D (2005) GABAergic inhibition controls neural gain in inferior colliculus neurons sensitive to interaural time differences. J Neurosci 25:6187-6198. CrossRef Medline

Isaacson JS, Scanziani M (2011) How inhibition shapes cortical activity. Neuron 72:231-243. CrossRef Medline

Keidel WD, Spreng M (1965) Neurophysiological evidence for the stevens power function in man. J Acoust Soc Am 38:191-195. CrossRef Medline

King JL, Lowe MP, Stover KR, Wong AA, Crowder NA (2016) Adaptive processes in thalamus and cortex revealed by silencing of primary visual cortex during contrast adaptation. Curr Biol 26:1295-1300. CrossRef Medline

Kluender KR, Stilp CE, Kiefte M (2013) Perception of vowel sounds within a biologically realistic model of efficient coding. In: Vowel inherent spectral change (Morrison GS, Assmann PF, eds), pp 117-151. Berlin, Heidelberg: Springer.

Knipper M, Van Dijk P, Nunes I, Rüttiger L, Zimmermann U (2013) Advances in the neurobiology of hearing disorders: recent developments regarding the basis of tinnitus and hyperacusis. Prog Neurobiol 111:1733. CrossRef Medline

Kvale MN, Schreiner CE (2004) Short-term adaptation of auditory receptive fields to dynamic stimuli. J Neurophysiol 91:604-612. CrossRef Medline

Laffont F, Bruneau N, Roux S, Agar N, Minz M, Cathala HP (1989) Effect of age on auditory evoked responses (AER) and augmenting-reducing. Neurophysiol Clin 19:15-23. CrossRef Medline

Lanting CP, Briley PM, Sumner CJ, Krumbholz K (2013) Mechanisms of adaptation in human auditory cortex. J Neurophysiol 110:973-983. CrossRef Medline

Laughlin S (1981) A simple coding procedure enhances a neuron's information capacity. Z Naturforsch C 36:910-912. Medline

Leek MR (2001) Adaptive procedures in psychophysical research. Percept Psychophys 63:1279-1292. Medline

Lewicki MS (2002) Efficient coding of natural sounds. Nat Neurosci 5:356363. Medline

Ling LL, Hughes LF, Caspary DM (2005) Age-related loss of the GABA synthetic enzyme glutamic acid decarboxylase in rat primary auditory cortex. Neuroscience 132:1103-1113. CrossRef Medline

Llano DA, Turner J, Caspary DM (2012) Diminished cortical inhibition in an aging mouse model of chronic tinnitus. J Neurosci 32:16141-16148. CrossRef Medline

Lü ZL, Williamson SJ, Kaufman L (1992) Human auditory primary and association cortex have differing lifetimes for activation traces. Brain Res 572:236-241. CrossRef Medline

Mäkelä JP, Ahonen A, Hämäläinen MS, Hari R, Ilmoniemi RJ, Kajola M, Knuutila J, Lounasmaa OV, McEvoy L, Salmelin R, Salonen O, Sams M, Simola J, Tesche C, Vasama JP (1993) Functional differences between auditory cortices of the two hemispheres revealed by whole-head neuromagnetic recordings. Hum Brain Mapp 1:48-56. CrossRef

Möhrle D, Ni K, Varakina K, Bing D, Lee SC, Zimmermann U, Knipper M, Rüttiger L (2016) Loss of auditory sensitivity from inner hair cell synaptopathy can be centrally compensated in the young but not old brain. Neurobiol Aging 44:173-184. CrossRef Medline

Morita T, Naito Y, Nagamine T, Fujiki N, Shibasaki H, Ito J (2003) Enhanced activation of the auditory cortex in patients with inner-ear hearing impairment: a magnetoencephalographic study. Clin Neurophysiol 114: 851-859. CrossRef Medline

Müller G, Stange G (1971) The input-output function of the slow auditory evoked potential in contralateral, ipsilateral, and vertex recordings. Arch Klin Exp Ohren Nasen Kehlkopfheilkd 198:116-127. CrossRef Medline

Müller MM, Keil A, Kissler J, Gruber T (2001) Suppression of the auditory middle-latency response and evoked gamma-band response in a pairedclick paradigm. Exp Brain Res 136:474-479. CrossRef Medline 
Nagel KI, Doupe AJ (2006) Temporal processing and adaptation in the songbird auditory forebrain. Neuron 51:845-859. CrossRef Medline

Nolte G (2003) The magnetic lead field theorem in the quasi-static approximation and its use for magnetoencephalography forward calculation in realistic volume conductors. Phys Med Biol 48:3637-3652. CrossRef Medline

Okamoto H, Kakigi R (2014) History of silence affects auditory evoked fields regardless of intervening sounds: a magnetoencephalographic study. Eur J Neurosci 40:3380-3386. CrossRef Medline

Olsen SR, Wilson RI (2008) Lateral presynaptic inhibition mediates gain control in an olfactory circuit. Nature 452:956-960. CrossRef Medline

Pascual-Marqui RD (2002) Standardized low resolution brain electromagnetic tomography (sLORTEA): technical details. Methods Find Exp Clin Pharmacol 24:5-12. Medline

Poldrack RA (2007) Region of interest analysis for fMRI. Soc Cogn Affect Neurosci 2:67-70. CrossRef Medline

Popelár J, Syka J, Berndt H (1987) Effect of noise on auditory evoked responses in awake guinea pigs. Hear Res 26:239-247. CrossRef Medline

Presacco A, Simon JZ, Anderson S (2016) Evidence of degraded representation of speech in noise, in the aging midbrain and cortex. J Neurophysiol 116:2346-2355. CrossRef Medline

Rabang CF, Parthasarathy A, Venkataraman Y, Fisher ZL, Gardner SM, Bartlett EL (2012) A computational model of inferior colliculus responses to amplitude modulated sounds in young and aged rats. Front Neural Circuits 6:77. CrossRef Medline

Rabinowitz NC, Willmore BD, Schnupp JW, King AJ (2011) Contrast gain control in auditory cortex. Neuron 70:1178-1191. CrossRef Medline

Robinson BL, McAlpine D (2009) Gain control mechanisms in the auditory pathway. Curr Opin Neurobiol 19:402-407. CrossRef Medline

Robinson BL, Harper NS, McAlpine D (2016) Meta-adaptation in the auditory midbrain under cortical influence. Nat Commun 7:13442. CrossRef Medline

Rosburg T, Trautner P, Korzyukov OA, Boutros NN, Schaller C, Elger CE, Kurthen M (2004) Short-term habituation of the intracranially recorded auditory evoked potentials P50 and N100. Neurosci Lett 372:245249. CrossRef Medline

Rosburg T, Trautner P, Boutros NN, Korzyukov OA, Schaller C, Elger CE, Kurthen M (2006) Habituation of auditory evoked potentials in intracranial and extracranial recordings. Psychophysiology 43:137-144. CrossRef Medline

Rosburg T, Zimmerer K, Huonker R (2010) Short-term habituation of auditory evoked potential and neuromagnetic field components in dependence of the interstimulus interval. Exp Brain Res 205:559-570. CrossRef Medline

Rosenthal R, Rubin DB (2003) requivalent: a simple effect size indicator. Psychol Methods 8:492-496. CrossRef Medline

Salinas E, Thier P (2000) Gain modulation: a major computational principle of the central nervous system. Neuron 27:15-21. CrossRef Medline

Salvi R, Sun W, Ding D, Chen GD, Lobarinas E, Wang J, Radziwon K, Auerbach BD (2016) Inner hair cell loss disrupts hearing and cochlear function leading to sensory deprivation and enhanced central auditory gain. Front Neurosci 10:621. CrossRef Medline

Sams M, Hari R, Rif J, Knuutila J (1993) The human auditory sensory memory trace persists about 10 sec: neuromagnetic evidence. J Cogn Neurosci 5:363-370. CrossRef Medline

Sato TK, Haider B, Häusser M, Carandini M (2016) An excitatory basis for divisive normalization in visual cortex. Nat Neurosci 19:568-570. CrossRef Medline

Saxe R, Brett M, Kanwisher N (2006) Divide and conquer: a defense of functional localizers. Neuroimage 30:1088-1096; discussion 1097-1099. CrossRef Medline

Sherman SM, Guillery RW (1998) On the actions that one nerve cell can have on another: distinguishing 'drivers' from 'modulators'. Proc Natl Acad Sci U S A 95:7121-7126. CrossRef Medline

Silver RA (2010) Neuronal arithmetic. Nat Rev Neurosci 11:474-489. CrossRef Medline

Simpson AJR, Harper NS, Reiss JD, McAlpine D (2014) Selective adaptation to "oddball" sounds by the human auditory system. J Neurosci 2014:1963-1969.

Sörös P, Teismann IK, Manemann E, Lütkenhöner B (2009) Auditory tem- poral processing in healthy aging: a magnetoencephalographic study. BMC Neurosci 10:34. CrossRef Medline

Stolzberg D, Chrostowski M, Salvi RJ, Allman BL (2012) Intracortical circuits amplify sound-evoked activity in primary auditory cortex following systemic injection of salicylate in the rat. J Neurophysiol 108:200-214. CrossRef Medline

Stothart G, Kazanina N (2016) Auditory perception in the aging brain: the role of inhibition and facilitation in early processing. Neurobiol Aging 47:23-34. CrossRef Medline

Suga N, Gao E, Zhang Y, Ma X, Olsen JF (2000) The corticofugal system for hearing: recent progress. Proc Natl Acad Sci U S A 97:11807-11814. CrossRef Medline

Syka J, Rybalko N, Popelár J (1994) Enhancement of the auditory cortex evoked responses in awake guinea pigs after noise exposure. Hear Res 78:158-168. CrossRef Medline

Takesian AE, Kotak VC, Sanes DH (2009) Developmental hearing loss disrupts synaptic inhibition: implications for auditory processing. Future Neurology 4:331-349. CrossRef Medline

Takesian AE, Kotak VC, Sanes DH (2012) Age-dependent effect of hearing loss on cortical inhibitory synapse function. J Neurophysiol 107:937-947. CrossRef Medline

Taulu S, Kajola M, Simola J (2004) Suppression of interference and artifacts by the signal space separation method. Brain Topogr 16:269-275. Medline

Taulu S, Simola J, Kajola M (2005) Applications of the signal space separation method. IEEE Transactions on Signal Processing 53:3359-3372. CrossRef

Tesche CD, Uusitalo MA, Ilmoniemi RJ, Huotilainen M, Kajola M, Salonen O (1995) Signal-space projections of meg data characterize both distributed and well localized neuronal sources. Electroencephalogr Clin Neurophysiol 95:189-200. CrossRef Medline

Tremblay KL, Piskosz M, Souza P (2003) Effects of age and age-related hearing loss on the neural representation of speech cues. Clin Neurophysiol 114:1332-1343. CrossRef Medline

Tyler RS, Pienkowski M, Roncancio ER, Jun HJ, Brozoski T, Dauman N, Coelho CB, Andersson G, Keiner AJ, Cacace AT, Martin N, Moore BC (2014) A review of hyperacusis and future directions: Part I. Definitions and manifestations. Am J Audiol 23:402-419. CrossRef Medline

Uusitalo MA, Ilmoniemi RJ (1997) Signal-space projection method for separating MEG or EEG into components. Med Biol Eng Comput 35:135140. CrossRef Medline

Wark B, Lundstrom BN, Fairhall A (2007) Sensory adaptation. Curr Opin Neurobiol 17:423-429. CrossRef Medline

Watkins PV, Barbour DL (2008) Specialized neuronal adaptation for preserving input sensitivity. Nat Neurosci 11:1259-1261. CrossRef Medline

Wen B, Wang GI, Dean I, Delgutte B (2009) Dynamic range adaptation to sound level statistics in the auditory nerve. J Neurosci 29:13797-13808. CrossRef Medline

Wen B, Wang GI, Dean I, Delgutte B (2012) Time course of dynamic range adaptation in the auditory nerve. J Neurophysiol 108:69-82. CrossRef Medline

Whitmire CJ, Stanley GB (2016) Rapid sensory adaptation redux: a circuit perspective. Neuron 92:298-315. CrossRef Medline

Wilson NR, Runyan CA, Wang FL, Sur M (2012) Division and subtraction by distinct cortical inhibitory networks in vivo. Nature 488:343-348. CrossRef Medline

Winer JA, Lee CC (2007) The distributed auditory cortex. Hear Res 229:313. CrossRef Medline

Zacharias N, König R, Heil P (2012) Stimulation-history effects on the M100 revealed by its differential dependence on the stimulus onset interval. Psychophysiology 49:909-919. CrossRef Medline

Zeng FG (2013) An active loudness model suggesting tinnitus as increased central noise and hyperacusis as increased nonlinear gain. Hear Res 295: 172-179. CrossRef Medline

Zhang F, Deshpande A, Benson C, Smith M, Eliassen J, Fu QJ (2011) The adaptive pattern of the auditory N1 peak revealed by standardized lowresolution brain electromagnetic tomography. Brain Res 1400:42-52. CrossRef Medline 